\title{
No fim, o bibliotecário morre ...
}

\author{
Regina Keiko Obata F. Amaro
}

\section{Resumo}

Apresenta organização e classificação dos sistemas de informação e cultura revistas a partir de $O$ Nome da rosa, livro e filme. Destaca a representação como abordagem conceitual. Amplia a noção de linguagem estabelecida para o Sistema de Recuperação da Informação (SRI) e propõe a identificação de várias linguagens como constituintes dos sistemas de informação e cultura. Essas linguagens, tomadas como instrumentos conceituais e operacionais, são utilizadas para a análise da obra em questão.

\section{Palavras-chave}

Sistemas de informação e cultura; Sistema de Recuperação da Informação (SRI); Representação; Linguagem; O Nome da rosa

\section{At the end, the librarian dies...}

\begin{abstract}
Organization and classification of the information and culture systems reviewed starting from The Name of the rose, book and film. Representation is the conceptual approach. The language notion used on Information Retrieval Systems (IRS) is broadened. Proposes the identification of several languages as constituents of the information and culture systems. These languages, taken as conceptual and operational tools, are used for the analysis.
\end{abstract}

\section{Keywords}

Information and culture systems; Information Retrieval Systems (IRS); Representing; Language; The Name of the rose 


\section{INTRODUÇÃO}

Nas palavras de Umberto Eco, "um título, infelizmente, é uma chave interpretativa" (ECO, 1985, p. 8). Isso seria absolutamente verdadeiro, caso A abadia do crime tivesse sido o título efetivamente escolhido para o seu primeiro romance. $\mathrm{O}$ autor abandona essa idéia porque "fixaria a atenção do leitor apenas sobre a intriga policial e poderia, injustamente, induzir alguns leitores sem sorte, à cata de histórias cheias de ação, a lançar-se sobre um livro que os teria enganado” (ECO, 1985, p. 8-9). Para o semiólogo, que nos brindou com o conceito de "obra aberta" (ECO, 1976b), "um título deve confundir as idéias, nunca discipliná-las” (ECO, 1985, p. 9).

A escolha de O Nome da rosa é perfeita. Utiliza uma figura fortemente simbólica, dotada de incontáveis e variados significados. Assim, não é possível fazer um único percurso de leitura e escolher uma única interpretação. Mesmo após mais de 25 anos do seu lançamento, ainda não se esgotaram e, certamente, nunca se esgotarão, as interpretações possíveis no universo de significação desse romance.

Sorte dos leitores, entre os quais, aqueles que se ocupam da construção dos saberes e fazeres da Ciência da Informação.

Para um "leitor ingênuo" 1 , O Nome da rosa é um romance policial. Já para o leitor que foi atraído para a armadilha arquitetada pelo autor, desvendar o mistério das várias mortes que acontecem na abadia é um verdadeiro processo de investigação que traz à luz, entre outras interpretações, um complexo sistema de organização e classificação, concebido e implementado de forma a cumprir, até as últimas conseqüências, todos os objetivos que caracterizam aquela Biblioteca, ou seja, uma biblioteca de conservação².

Penetrar no labirinto, subir e descer escadarias que se dirigem a inúmeros becos sem saída, sombrios e assustadores, escapar das artimanhas dos monstros e demônios, safar-se dos calabouços que conduzem à danação do inferno, continuar vivo mesmo depois de ler o livro proibido e, finalmente, escapar do fogo redentor e sair do Edifício em chamas.

1 Conforme ECO (1985, p.45). Ressaltamos que, para nós, “leitor” tem um significado ampliado que recobre a leitura de todas as linguagens, verbais e não-verbais. Portanto, no caso deste artigo, referimo-nos tanto ao leitor do livro quanto ao leitor do filme.

2 Em trabalhos anteriores (AMARO, 1998; OBATA, 1999), propomos os paradigmas conservação e difusão, identificados em momentos históricos distintos, como determinantes para a construção das concepções de biblioteca. Esses paradigmas possibilitam a sistematização de indicadores constituintes dos conceitos de biblioteca de conservação e biblioteca de difusão. O Nome da rosa foi utilizado na discussão dessas idéias.

(C) Revista Digital de Biblioteconomia e Ciência da Informação, Campinas, v. 4, n. esp. , p. 72-88, 2006 - ISSN: 1678-765X. 
Esta aventura de frei Guilherme (no filme, William, o nome em inglês), acompanhado de seu discípulo, o noviço Adso; é o percurso para desvendar, decifrar, decodificar a linguagem da Biblioteca.

\section{LINGUAGENS E REPRESENTAÇÕES}

A idéia de a linguagem ser elemento fundamental na constituição de quaisquer serviços, unidades ou redes de informação e cultura, tem sido decisiva para os estudos que realizamos nos últimos anos (AMARO, 1998, 2005; OBATA, 1999). Essa formulação foi possível, a partir da pesquisa sobre a análise documentária de textos jornalísticos (AMARO, 1992) que, entre outros resultados, mostrou a possibilidade de uma abordagem das questões relativas aos processos e instrumentos do Sistema de Recuperação da Informação (SRI), distinta daquela adotada por inúmeros especialistas ${ }^{3}$. No fluxo deste sistema, a linguagem define-se como Linguagem Documentária, instrumento utilizado na representação enquanto uma etapa do processo de indexação, ou seja, representação do conteúdo dos recursos informacionais.

Para nós, no entanto, a premissa orientadora das ações e práticas objeto da Ciência da Informação, é expressa pelas noções representação da representação e construção de significações. A pertinência dessa formulação justifica-se pelo fato de que nos sistemas de informação e cultura operamos com objetos que, de antemão, constituem-se em representações ${ }^{4}$. E, são esses objetos-representações que serão submetidos aos processos de representação, não só daqueles amplamente conhecidos (representação descritiva e representação temática dos recursos informacionais), como também do processo de construção de significações das várias linguagens de um sistema de informação e cultura. Assim, a noção de linguagem amplia-se e a Linguagem Documentária torna-se tão somente uma das linguagens do sistema.

\footnotetext{
${ }^{3}$ Para evitar uma lista extensa pouco relacionada com a essência do presente artigo, citamos ao menos a obra Indexação e resumos: teoria e prática, em tradução publicada por Briquet de Lemos Livros, em 1993. Seu autor, o estudioso americano F. W. Lancaster, é reconhecido como referência na área.

${ }^{4}$ Essa formulação é similar a um diálogo sobre a construção do conhecimento em que, a certa altura, Guilherme afirma que "a idéia é signo das coisas, e a imagem é signo de uma idéia, signo de um signo" (ECO, 1983, p. 362).
} 
Na análise dessas linguagens, tanto para a construção quanto avaliação de um sistema/serviço de informação e cultura, é fundamental a sua contextualização, principalmente em termos da identificação dos seus objetivos essenciais e primordiais. Por isso, antes da análise das linguagens dos sistemas de organização e classificação da biblioteca objeto deste artigo, devemos conhecer as políticas que orientam essa instituição.

\subsection{O cenário das representações}

A história de O Nome da rosa transcorre no início do declínio do poder do papado; devotos viviam como ermitãos em grupos ou em novas ordens monásticas nas quais havia grande incentivo à erudição. Nesses monastérios, parte da cultura grega e romana e também de outras regiões, era preservada.

Os fatos acontecem durante sete dias, em fins de novembro de 1327, no interior de uma rica e famosa abadia da Idade Média italiana, construída no alto de uma montanha, cercada por pesadas muralhas.

A biblioteca é descrita como escrínio ${ }^{5}$, reconhecida por todos como a maior e a mais importante do mundo cristão. O acervo, formado ao longo de séculos, continha obras produzidas em todas as partes do mundo conhecido na época. A riqueza do acervo é evidenciada na cena em que, ao finalmente conseguir entrar na primeira sala dos livros, Guilherme, diz para Adso: "Eu sabia! Eu sabia! Percebes que estais numa das maiores bibliotecas da cristandade?” e, solta um grito-riso de felicidade e emoção.

A cópia e a tradução de manuscritos eram, muitas vezes, autorizadas para monges de outras abadias espalhadas pelo mundo inteiro, em troca de exemplares raros que a biblioteca ainda não possuía. Eram milhares de livros que continham a verdade da palavra divina, mas havia também aqueles que continham as mentiras dos infiéis. A biblioteca é o lugar da reserva do saber, onde se depositam livros para se preservar e não para se ler ou se investigar; depósito do conhecimento e das idéias que deve se manter intacto, a salvo de todos. Encerra segredos que somente alguns poucos escolhidos podem conhecer. Ela guarda verdades e mentiras que devem ser rigorosamente preservadas e protegidas, tanto da natureza quanto, principalmente, dos homens (ECO, 1983, p. 52-4).

\footnotetext{
${ }^{5}$ Porta-jóia.
} 
Diferentemente do entendimento imediato de que os monges ou os membros da Igreja são os únicos usuários da biblioteca, na verdade, nem mesmo eles podiam ter acesso a ela ou utilizar o seu acervo. No scriptorium, os monges faziam uso de determinados livros, somente para realizar o trabalho de cópia ou tradução, para a própria biblioteca e não para fazer pesquisa.

Nas palavras do Abade, somente o bibliotecário sabia e tinha o direito de moverse entre os livros para encontrá-los e guardá-los. Somente ele é responsável pela sua conservação e sabe "o grau de sua inacessibilidade, que tipo de segredos, de verdades ou de mentiras o volume encerra. Somente ele decide como, e se deve fornecê-lo ao monge que o está requerendo, às vezes após ter-se consultado comigo” (ECO, 1983, p. 54). E mais, "somente o bibliotecário recebeu o segredo do bibliotecário que o precedeu, e o comunica, ainda em vida, ao ajudante-bibliotecário, de modo que a morte não o surpreenda, privando a comunidade desse saber. E os lábios de ambos estão selados pelo segredo” (idem, p. 53). É importante acrescentar que, na linha sucessória descrita, o bibliotecário será, no futuro, Abade.

\section{SISTEMAS DE ORGANIZAÇÃO E CLASSIFICAÇÃO: REPRESENTAÇÕES E SIGNIFICAÇÕES}

A biblioteca "[...]nasceu segundo um desenho que permaneceu obscuro a todos durante séculos e que a nenhum dos monges é dado conhecer” (ECO, 1983, p. 53). Vemos que o desenho perfeito para cumprir essa missão é o labirinto, figura inquietante, tanto concreta como simbolicamente. É considerado um arquétipo da vida e da consciência do homem que impõe um percurso verdadeiro e falso. Segundo Borges, o labirinto é a metáfora do livro: lugar em que se perde, faz-se aposta para perder-se, para desorientar-se. Um livro é labiríntico; ele tenta reproduzir a Biblioteca Universal que, como toda biblioteca, também é labiríntica (BORGES, 1999).

O significado do labirinto é praticamente impossível de ser compreendido na sua totalidade; as representações a ele atribuídas, nas mais variadas áreas do conhecimento, reforçam toda a complexidade e amplitude de significações e interpretações. Entre as várias linguagens da biblioteca de $O$ Nome da rosa, o labirinto é a de reconhecimento imediato e tem sido, com freqüência, objeto de discussão e análises. Considerando, como Eco, que o labirinto é um modelo de conjeturas (ECO, 1985, p. 46), propomos também uma possibilidade de interpretação. 


\subsection{Labirinto, obstáculos e códigos secretos: linguagens de organização do sistema}

Se a estrutura em labirinto da biblioteca é um modelo de conjecturas, podemos dizer que a sua exploração exige a formulação de hipóteses, tal como o processo metodológico hipotético-dedutivo de leitura proposto por autores como van Dijk (1978, 1980) e aplicado em discursos jornalísticos por Amaro (1992). Sendo assim, consideramos o labirinto uma linguagem que deve ser efetivamente lida como uma das linguagens da biblioteca.

Nas palavras do abade, a biblioteca não é somente "labirinto espiritual, é também labirinto terreno. Podereis entrar e poderíeis não sair” (ECO, 1983, p. 55). As imagens do filme tornam este "discurso" da biblioteca muito concreto e real, permitindo que se faça dela, uma boa leitura. É oportuno citar a gravura Relatividade, de Escher (Fig. 1), como uma representação especialmente intrigante desse labirinto.

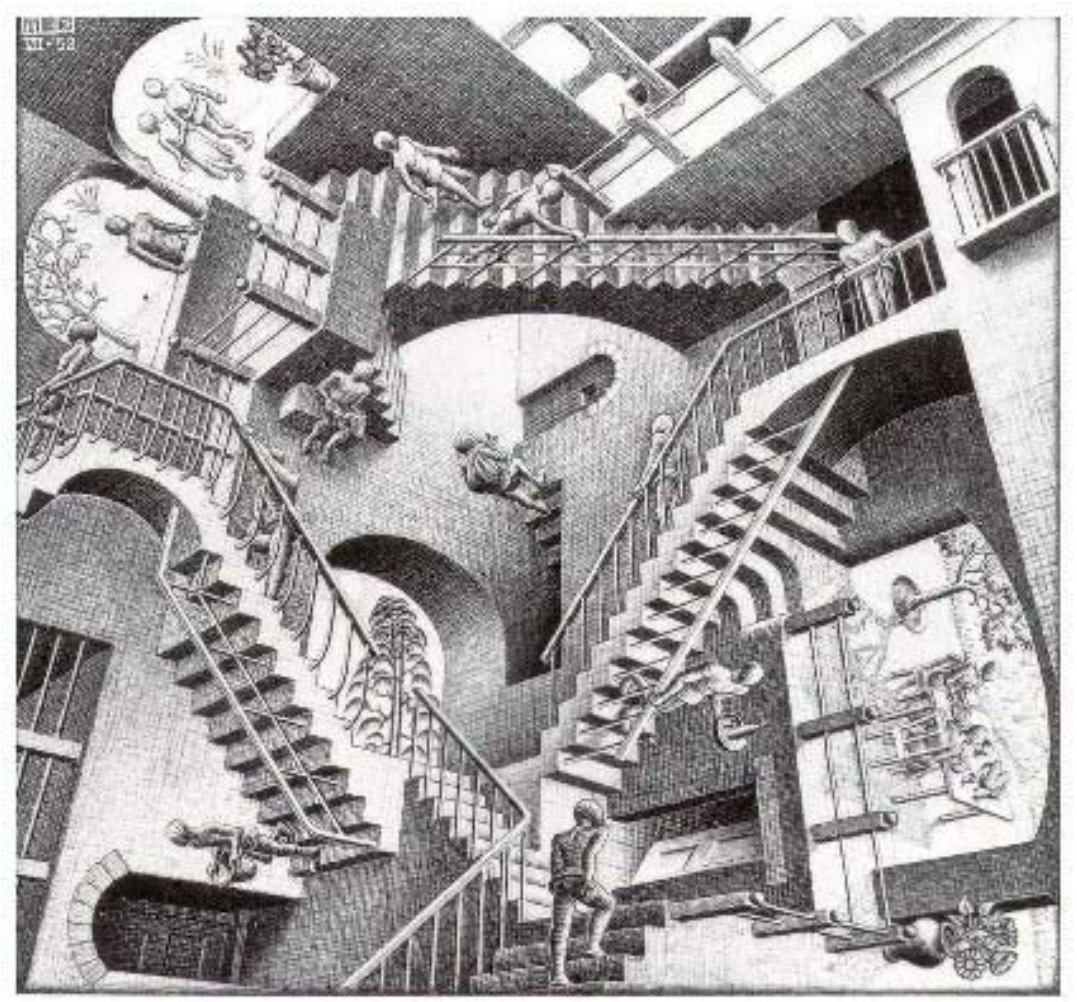

FIG. 1: M.C. Escher. La relativité, 1953, litografia 272x293

Durante o percurso no interior do labirinto-biblioteca, quando uma hipótese de direção se confirma, significa que a interpretação foi adequada, possibilitando um avanço

(C) Revista Digital de Biblioteconomia e Ciência da Informação, Campinas, v. 4, n. esp. , p. 72-88, 2006 - ISSN: 1678-765X. 
na sua exploração; caso a hipótese não seja verdadeira, o sujeito deve recuar e construir uma nova hipótese, até que possa, enfim, seguir adiante. Evidentemente, no caso da leitura do labirinto-biblioteca, as hipóteses devem ser, todas elas, lógicas e bem fundamentadas, caso contrário, o sujeito ficará perdido ad aeternum.

No entanto, ele não se perde somente por causa da estrutura labiríntica. Há inúmeros outros obstáculos que devem ser enfrentados, para não sucumbir.

Durante o percurso surgem monstros, figuras do demônio para fazê-lo lembrar-se do pecado que está cometendo, desafiando a sua objetividade e racionalidade. Se, mesmo assim, o sujeito não desistir, abrem-se alçapões que o conduzem para as profundezas do inferno.

Para, de fato, seguir adiante, é preciso decodificar a linguagem estabelecida e entender que esses fenômenos são produzidos pelo imaginário, a partir de espelhos reais que deformam as imagens, somados a substâncias - ervas mágicas - colocadas durante a noite, capazes de provocar visões para convencer os inoportunos de que a biblioteca é defendida por presenças diabólicas. Há também um sistema de ventilação muito bem planejado pelos engenhosos fundadores, não só para manter a atmosfera respirável e a umidade necessária para os pergaminhos, mas também para criar um ambiente assustador: as fendas são dispostas de tal forma que, com o vento das noites, os sopros penetram e se cruzam com outros sopros, produzindo sons aterrorizantes, como se houvesse fantasmas e outros seres malignos. O próprio Guilherme, após decifrar essa linguagem, conclui que "este lugar de sabedoria proibida é protegido por muitos e sapientíssimos achados. A ciência é usada para ocultar e não para iluminar” (ECO, 1983, p. 206).

As escadas e corredores escuros, estreitos e tortuosos podem levar a muitos caminhos sem saídas ou a salas onde estão depositados os livros. Estes são registrados segundo a ordem de chegada através de compra, doação ou permuta, em volumoso códice, preso à mesa do bibliotecário por uma corrente de ouro. Ao lado de cada título, encontramse anotações que são, de fato, os códigos de localização (como um número de chamada dos dias atuais). Por exemplo, ii, V gradus, VII in quarta acaiae, que frei Guilherme, decifra: posição de número 2 na estante número 5 (ii, V gradus), do armário número 7 (VII) e a outra expressão (in quarta acaiae) designa uma sala ou corredor da biblioteca. Questionando sobre a ordem em que são colocados os livros, ele mesmo deduz que não é por assunto (ECO, 1983, p.95). 
Essa é a linguagem da organização espacial da biblioteca e também da organização dos próprios livros; representa a idéia do proibido e inacessível; constrói um universo de significação do pecado, do medo, do castigo.

Mas, para os que desejam transpor esses obstáculos, restam ainda outras indagações: os códigos indicam qual sala, qual corredor? Como encontrá-la no interior do terrível labirinto? O que significaria a última expressão?

\subsection{O sistema de classificação: representações e significações}

O próprio Guilherme nos orienta no caminho para se desvendar os códigos que organizam os livros. Ao encontrar um pedaço de pergaminho que caíra da mesa de Venâncio, o tradutor grego morto, descobre que, à contraluz é possível ler, escrito com limão, uns traços que não pareciam de nenhum alfabeto conhecido; pareciam símbolos do zodíaco. Nas suas palavras,

a primeira regra para decifrar uma mensagem é adivinhar o que ela quer dizer. [...] É possível formular hipóteses sobre as que poderiam ser as primeiras palavras da mensagem, e depois ver se a regra que daí se infere vale para todo o resto do escrito. [...] É preciso encontrar uma regra de correspondência [...] na cabeça. Inventá-la. E depois ver se é verdadeira” (ECO, 1983, p. 196-7).

Observamos que se descreve um processo similar ao do método hipotéticodedutivo de leitura, mencionado anteriormente.

Depois do insucesso de penetrar no labirinto com segurança, Guilherme resolve encontrar por fora, um modo de descrever o Edifício por dentro ${ }^{6}$ (ECO, 1983, p. 251). E assim foi feito: observando detalhadamente o traçado do lado externo do Edifício ${ }^{7}$, produziram um desenho da biblioteca. Faltava entender a disposição das passagens, ou seja, entender o próprio labirinto.

Com o desenho da biblioteca em mãos, era possível caminhar pelas salas, identificando aquelas que tinham portas e as salas cegas (sem saída); aos poucos, o labirinto

\footnotetext{
${ }^{6}$ Sobre essa idéia, Guilherme pergunta: “E porque é possível conhecer as coisas olhando-as de fora?”. Ele próprio responde: “é porque é assim que Deus conhece o mundo, porque o concebeu em sua mente, como se estivesse de fora, antes que fosse criado; enquanto nós não conhecemos a regra, porque vivemos dentro dele, encontrando-se já pronto” (ECO, 1983, p. 255).

7 Assim era designada a grande torre que encerrava a biblioteca.
} 
vai se formando no esquema e descobre-se que a biblioteca está construída segundo uma harmonia celeste, cujo traçado reproduz o mapa do mundo.

Mas, ainda é preciso saber como as salas foram codificadas e também se havia uma regra para a distribuição dos livros, dispostos com certa regularidade nos enormes armários; estes traziam uma etiqueta numerada, assim como cada uma de suas estantes. Evidentemente, aqueles mesmos números do catálogo.

Durante a caminhada, Guilherme e Adso, percebem que, em cada sala, no arco de uma de suas portas, está gravado com certa profundidade na pedra, versículo do Apocalipse de João; os sulcos foram pintados, a maioria na cor preta e, alguns, na cor vermelha. Às vezes, uma frase é repetida em salas distintas (ECO, 1983, p. 199-201). Observam que foi escolhido o número de versículos equivalente ao número de letras do alfabeto e que não é a frase que importa, mas a letra com a qual ela começa. Assim, cada sala é marcada por uma letra do alfabeto, e as letras juntas, numa seqüência, compõem um texto que se inicia pelas frases em vermelho (ECO, 1983, p. 254). Estava decifrada mais essa linguagem: sabia-se, agora, qual era o conjunto de códigos e como eles deveriam ser combinados. Além disso, não podemos esquecer que a biblioteca foi constituída e organizada segundo a imagem do orbe terrestre. Sendo assim, os livros são dispostos segundo os países de proveniência, o lugar onde nasceram seus autores ou o lugar onde deveriam ter nascido. Baseando-se nesses conhecimentos e raciocínios, Guilherme e Adso percorrem todas as salas da biblioteca e conseguem traçar o labirinto, cujo desenho reproduzimos a seguir (Fig. 2): 


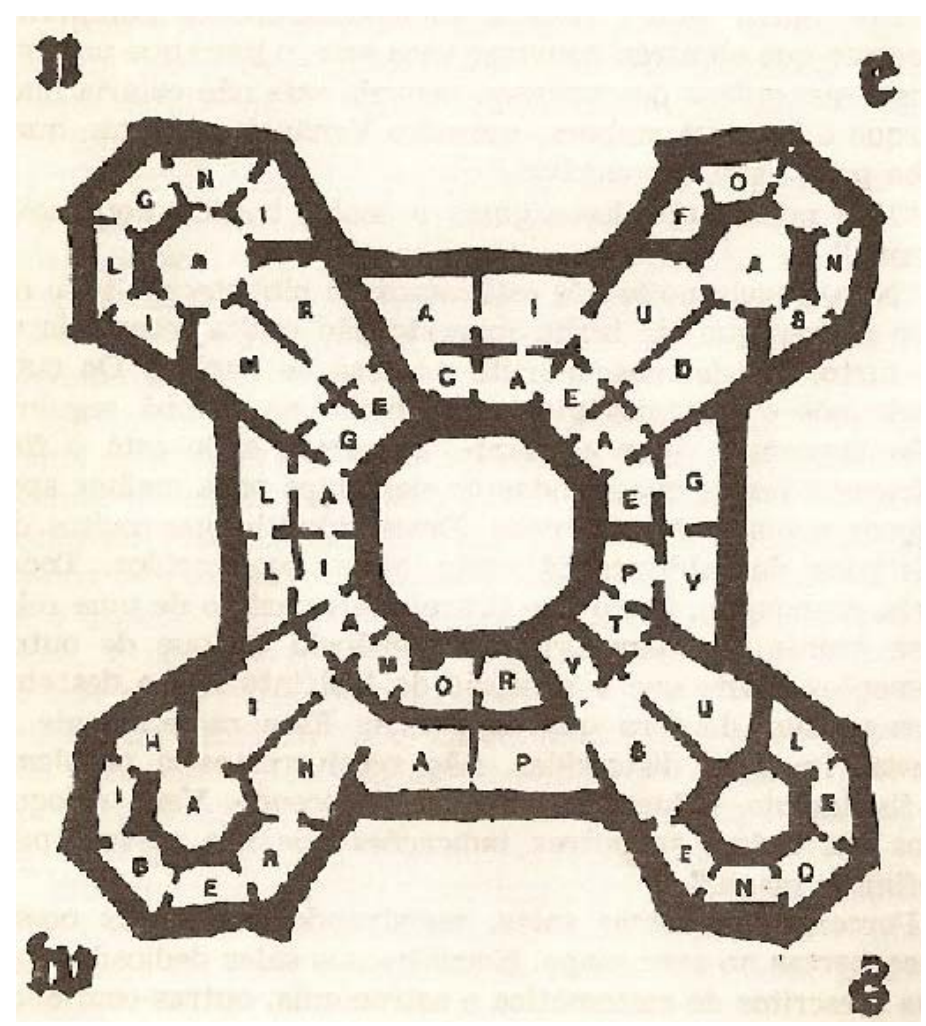

Fig. 2: Mapa da Biblioteca de O Nome da rosa (p. 366)

Vejamos a distribuição e disposição das $\operatorname{salas}^{8}$. Ao Norte $(\boldsymbol{n})$, encontram-se ANGLIA e GERMANI; observa-se que a letra A, da sala central, inicia e termina Anglia. Além disso, as salas A e $\mathbf{N}$, são ocupadas, ao mesmo tempo, por GermANi e AngliA, significando que havia salas com obras de caráter misto. Na parede ocidental, vemos GALLIA cuja sala correspondente ao A final faz a passagem para HIBERNIA, a Oeste $(\boldsymbol{W})$. Na parede interna Sul $(\boldsymbol{S})$, está ROMA e YSPANIA; no extremo Sul (S), LEONES. A sala $S$ de Leones é a mesma do final de AEGYPTUS que se encontra na parede oriental. Seguindo ainda para o oriente, vemos IUDAEA e, no Leste $(\boldsymbol{e})$, FONS ADAE (Paraíso Terrestre). Na parede, entre o Leste e o Norte, fica ACAIA distribuída em quatro salas dispostas em quadrado; portanto, o primeiro Aé também o último (ECO, 1983, p. 366-7).

Vemos que, de fato, o desenho reflete o mapa-múndi da época. Portanto, à primeira vista, como concluiu Guilherme, os livros são dispostos de acordo com uma classificação geográfica, levando-se em consideração a procedência da obra ou o local onde

${ }^{8}$ A correspondência aproximada dos países/regiões para a atualidade seria: Anglia (Inglaterra), Germani (Alemanha), Gallia (França), Hibernia (Irlanda), Roma (Itália), Yspania (Espanha), Aegyptus (Egito), Iudaea (Judéia, Palestina), Acaia (Grécia antiga); Leones (Leões, África). 
o autor nasceu. Assim, em Hibernia, estão os gramáticos hibérnicos; Roma, é o paraíso dos clássicos latinos; Acaia guardava uma profusão de poetas e filósofos da antiguidade pagã; em Leones, correspondente à África, encontra-se, por exemplo, o Corão, a bíblia dos infiéis, um livro perverso. É interessante observar que essa disposição das salas com identificação feita através das letras que compõe um nome geográfico, é também um artifício mnemônico ${ }^{9}$ para permitir ao bibliotecário encontrar uma obra. Por exemplo, no código que Guilherme lê no catálogo, mencionado anteriormente, quarta acaiae significa que o livro está em Acaia, na quarta sala a partir daquela que tem o A inicial (ECO, 1983, 358-60, 366-7).

No entanto, analisando mais atentamente, verificamos que os livros não estão armazenados sempre nas salas da região de sua procedência ou de seus autores. É o caso do gramático Virgílio que nasceu em Toulouse, mas por causa da sua especialidade deveria ter nascido nas ilhas ocidentais. Por isso, os bibliotecários "reparam os erros da natureza" (ECO, 1983, p. 359) e depositam as obras desse autor e de outros gramáticos, em Hibérnia. Em Leões, não há somente obras procedentes da África; este é o local dos monstros selvagens, portanto, mesmo dos livros científicos árabes que são considerados perigosos; é o lugar dos livros da mentira. Finalmente, Fons Adae não é uma região geográfica: é o Paraíso Terrestre em cujas salas estão as escrituras sagradas, bíblias e comentários à bíblia, ou seja, os livros da verdade.

O labirinto representado pelo mapa-múndi forma, de fato, um complexo sistema de classificação dos livros. ACAIA, AEGYPTUS, ANGLIA, FONS ADAE, GALLIA, GERMANI, HIBERNIA, IUDAEA, LEONES, ROMA, YSPANIA, são códigos de representação não só dos conteúdos dos livros, tais como, gramática, filosofia, poesia, ciência, religião, magia. Não podemos esquecer que há uma importante etapa no processo de análise, qual seja, a categorização "livros da verdade” e "livros da mentira”. Portanto, o sistema aplica-se, principalmente, para a representação dos conteúdos simbólicos dos livros, da biblioteca, da sociedade.

\footnotetext{
${ }^{9}$ Lembremos que para a construção da sua classificação decimal, Melvil Dewey estabelece o mnemônico como uma das características necessárias para o sistema; assim, a Classificação Decimal de Dewey e, posteriormente, a Classificação Decimal Universal apresentam este artifício.
} 


\subsection{A linguagem arquitetônica}

Há ainda um último conjunto de linguagens que, não por acaso, são as primeiras linguagens da biblioteca apresentadas, tanto no livro quanto no filme: a localização e a estrutura arquitetônica do Edifício (Figuras 3 e 4).

Para Eco, a Arquitetura pode ser considerada um sistema de signos, um fato de comunicação, mesmo sem excluir a sua funcionalidade. Sendo assim, o objeto arquitetônico pode denotar a função ou conotar uma ideologia da função. [...] É difícil dizer se essa sua natureza conotativa, essa sua "função" simbólica seria menos "funcional” do que a natureza denotativa. Nessa perspectiva, a qualificação de "função" passa a abarcar todas as destinações comunicacionais, visto que em sociedade, as conotações "simbólicas” do objeto útil não são menos úteis do que suas denotações “funcionais” (ECO, 1976a, p. 202).

É nessa medida que, para nós, a linguagem arquitetônica sintetiza, concreta e simbolicamente, todas as representações da Biblioteca.

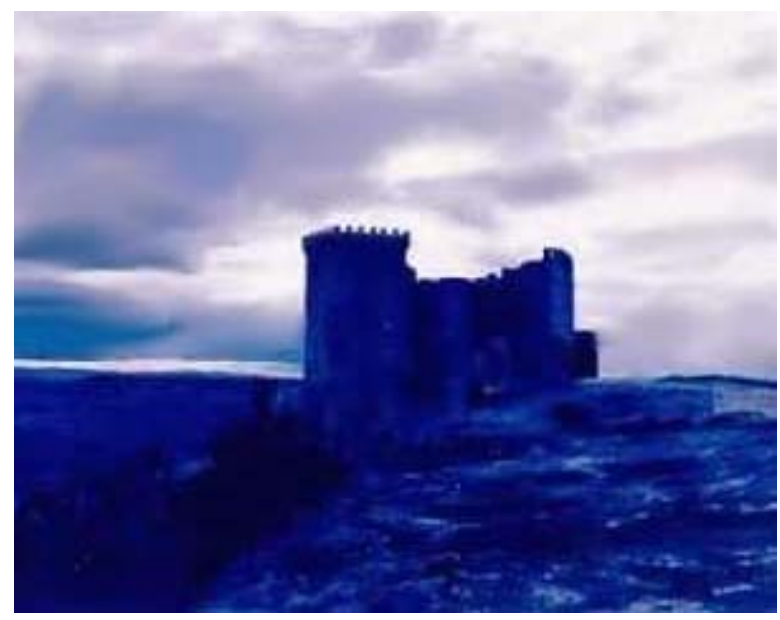

Fig. 3: Abadia medieval no topo das colinas

O Edifício encontra-se assentado no alto de colinas isoladas, distantes, inóspitas; para atingi-lo é preciso vencer caminhos árduos, difíceis, cansativos, como uma via sacra 
penitencial, iniciatória ${ }^{10}$. Quem não tiver forças, físicas e espirituais, não conseguirá chegar à biblioteca e, muito menos, aos livros; vai permanecer nas encostas da colina.

Se chegar ao topo, o Edifício ergue-se em grossas paredes, impenetráveis.

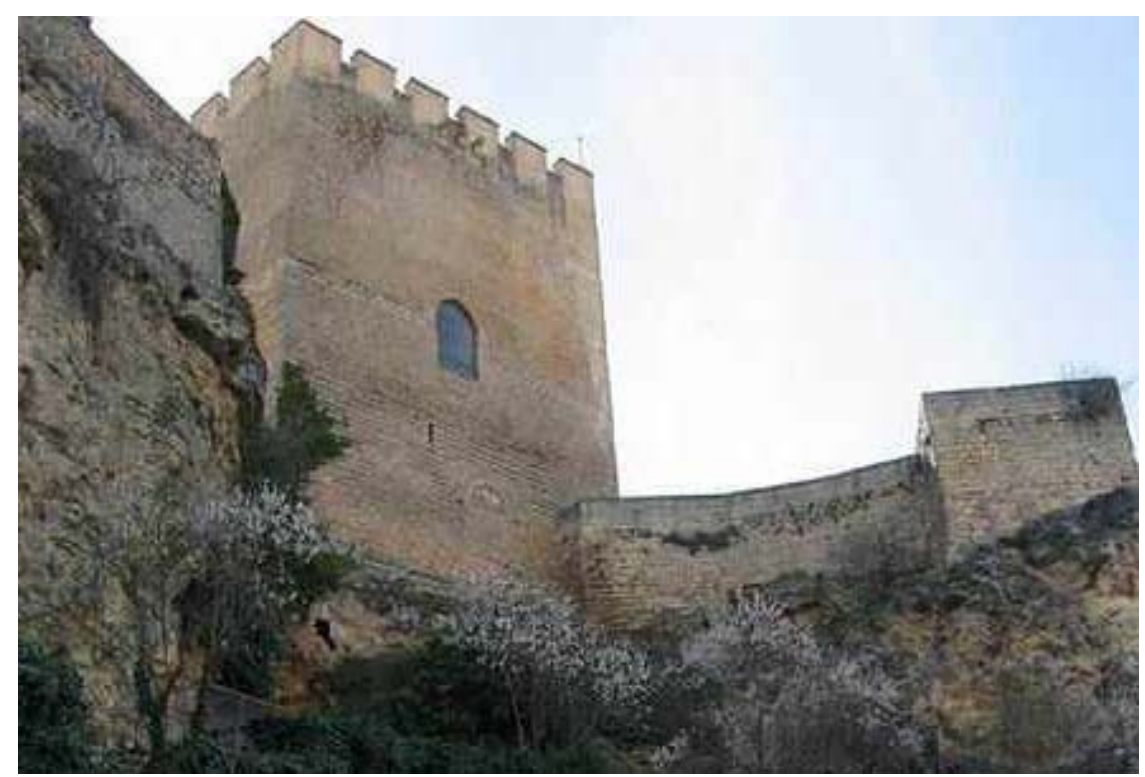

Fig. 4: Construção medieval como em O Nome da rosa

Há três possibilidades de entrar no labirinto-biblioteca. Pelo portal externo, pesado, incrustado com esculturas de figuras estranhas que fica permanentemente fechado; aberto, ele dá passagem às catacumbas sombrias, úmidas, assustadoras, repletas de ratos e ossadas humanas. Por dentro do Edifício, passando pelo scriptorium, existe uma porta com trancas pelo lado de dentro; quando aberta, é sempre vigiada pelo bibliotecário que diligentemente nega e impede a entrada na biblioteca ${ }^{11}$. E, finalmente, por um atalho secreto que só o venerável Jorge conhece e utiliza.

Essas linguagens constroem representações concretas e simbólicas do silêncio e da escuridão; do impenetrável e do proibido; da reserva do saber que deve se manter

${ }^{10}$ ECO faz alusão à função penitencial, iniciatória das primeiras cem páginas do livro, consideradas tão difíceis que os editores sugeriam eliminá-las; mas, segundo ele "se alguém quisesse entrar na abadia e viver nela sete dias, tinha que aceitar o seu ritmo” (ECO, 1985, p. 36).

${ }^{11} \mathrm{Na}$ cena em que Guilherme e Adso estão tentando abrir a porta que se encontrava encostada e, repentinamente, surge de dentro o bibliotecário, trava-se o seguinte diálogo: Guilherme: O auxiliar de biblioteca Berengário está aqui? - Malaquias: Não! - Guilherme: Sabes onde posso encontrá-lo? Malaquias: Não! - Guilherme: Talvez lá em cima, na biblioteca? - Malaquias: Não! - Guilherme: Tenho vontade de visitar a biblioteca. Posso? - Malaquias: Não!

(C) Revista Digital de Biblioteconomia e Ciência da Informação, Campinas, v. 4, n. esp. , p. 72-88, 2006 - ISSN: 1678-765X. 
intacto, a salvo de todos. A adequação de todas as linguagens protege a Biblioteca da natureza e, principalmente, dos homens, cumprindo assim, os seus objetivos.

\section{CONCLUSÃO}

O venerável Jorge de Burgos era o único conhecedor de todos os segredos da Biblioteca, vários deles criados por ele próprio. Era o único que fazia a leitura cotidiana de todas as suas linguagens secretas: a do conhecimento nela encerrado e das linguagens estruturadas para a sua preservação. Linguagens essas, concebidas para a construção não só física, mas especialmente, simbólica da Biblioteca.

E, afinal, como e por que o bibliotecário Malaquias morre? Pela língua, como alguns dos que morreram. E isso aconteceu porque ele ainda não conhecia a derradeira e fatal regra do código da biblioteca: livros proibidos não são perigosos somente para o espírito; eles também podem matar. O bibliotecário ainda não estava pronto para conhecer o último segredo da missão confiada por Deus àquela Abadia: conservar, repetir e defender o tesouro da sabedoria de várias gerações, de todos os lugares, da verdade e da mentira. O bibliotecário cumpria fielmente as tarefas que lhe cabiam, ou seja, orientava-se a partir do questionamento Como se faz? Por isso, não dominava todas as linguagens que construíam o significado da missão que a ele estava destinada, a de guardião da palavra divina. Isso só seria possível se a sua ação fosse consolidada a partir das bases conceituais resultantes dos questionamentos Por quê, para que e para quem. Ou seja, há que se identificar as concepções norteadoras da construção cotidiana da biblioteca (AMARO, 1998, p. 9-10). A morte é o castigo para esse desconhecimento.

Sabemos que o venerável Jorge é um assassino e, também, porque ele precisa matar. Mas por quê ele morre? Lembremos de uma das bases conceituais da Biblioteca: "Somente o bibliotecário recebeu o segredo do bibliotecário que o precedeu, e o comunica, ainda em vida, ao ajudante-bibliotecário, de modo que a morte não o surpreenda, privando a comunidade desse saber. E os lábios de ambos estão selados pelo segredo” (ECO, 1983, p. 53). Ocorre que o ajudante-bibliotecário morreu; e, lamentavelmente ${ }^{12}$, o bibliotecário também morreu antes de conhecer o último segredo. Além disso, desgraçadamente, frei Guilherme decodifica todas as linguagens da biblioteca, desvenda o segredo e... não morre! Dessa forma, ele desconstrói a estrutura lógica e simbólica da Biblioteca. Ao venerável, só

${ }^{12}$ De fato, no filme, ao saber da morte do bibliotecário, o venerável Jorge exclama: “Santo Deus!!! Não Malaquias!!!”

(c) Revista Digital de Biblioteconomia e Ciência da Informação, Campinas, v. 4, n. esp. , p. 72-88, 2006 - ISSN: 1678-765X 
resta a solução extrema de destruir a Biblioteca e a si próprio, consumidos pelo fogo cujas chamas purificam. Cumprem-se, assim, os desígnios de Deus ${ }^{13}$ para a missão da biblioteca que jamais poderão ser contrariados: preservar e não perscrutar ${ }^{14}$.

Desde o início da civilização, o progresso da humanidade está vinculado à capacidade do homem de registrar os seus sonhos e realizações. E, ao lado da necessidade de fazer registros, as bibliotecas surgiram e passaram por sistematizações políticas, administrativas e técnicas dentro de uma logicidade, constituída ao longo do tempo (AMARO, 1998).

Na contemporaneidade, vigora a concepção de biblioteca de difusão, atualizada com as noções de recuperação e disseminação da informação, com a parceria das novas tecnologias (AMARO, 1998; OBATA, 1999). Essas tecnologias de informação e comunicação impõem uma dimensão global de inúmeras questões culturais, sociológicas, psicológicas, econômicas, políticas, que colocam o sujeito frente a um novo labirinto, mais sofisticado, impreensível, imaterial, evanescente, evasivo e invasivo. É cada vez mais pertinente uma frase de Guilherme: nunca duvide da verdade dos signos; são a única coisa de que dispõe o homem para se orientar no mundo.

\section{REFERÊNCIAS}

AMARO, R. K. O. F. Biblioteca Interativa: concepção e construção de um serviço de informação em ambiente escolar. São Paulo, 1998. Tese (Doutorado em Ciência da Comunicação) - Escola de Comunicações e Artes da USP.

et. all. Biblioteca como ambiente educativo de informação e cultura para jovens. In: HENNING, Wolfran. Arquitetura de biblioteca. Disponível em <http://www.goethe.de/ins/br/sap/wis/sbi/fav>. Acesso em 20/08/2006.

. Construção interativa da biblioteca escolar. In: MACEDO, N. D. (Org.) Biblioteca escolar brasileira em debate. São Paulo: Editora Senac: CRB-8, 2005. p. 304-13.

\footnotetext{
${ }^{13}$ Na verdade, dos homens! Nesse caso, de alguns homens...

${ }^{14}$ No filme, com essas palavras, proferidas em um sermão contundente, o venerável Jorge deixa claro, mais uma vez, a política de construção secular e cotidiana da Biblioteca. Perscrutar significa investigar, devassar, procurar conhecer, estudar, penetrar, esquadrinhar.
} 
AMARO, R. K. O. F. Elementos de análise do discurso para a análise documentária aplicada à documentação jornalística. In: MELO, J.M. ; CARVALHO, M. R. de (org.). Anuário de Inovações em Comunicações e Artes. São Paulo: ECA/USP, 1992. p. 273288.

BASHIRUDDIN, S. The story of the library over the centuries. In: GIDWANI, N. N. (ed.) Foundations of library science. Bombay (Índia) : Hans Publishers, 1968.

BORGES, J. L. O Aleph. Rio de Janeiro : Globo, 1999. - 1ª edição original em 1949).

ECO, U. A estrutura ausente. São Paulo: Perspectiva, 1976a.

O Nome da rosa. Rio de Janeiro: Nova Fronteira, 1983.

Obra aberta. São Paulo: Perspectiva, 1976b.

Pós-escrito a O Nome da rosa. Rio de Janeiro: Nova Fronteira, 1985.

OBATA, R. K. Biblioteca Interativa: construção de novas relações entre biblioteca e educação. R. Bras. Bibliotecon. Doc., São Paulo, Nova Série, v. 1, n. 1, p. 91-103.

O NOME da rosa. Direção: Jean-Jacques Annaud. França, Itália, Alemanha: Constantin Film Produktion GmbH, 1986. 131 min., Colorido.

VAN DIJK, T. A. Gramáticas textuais e estruturas narrativas. In: SEMIÓTICA narrativa e textual. São Paulo: Cultrix: EDUSP, 1977. 


\section{Regina Keiko Obata F. Amaro}

Professora Doutora do Departamento de Biblioteconomia e Documentação da Escola de Comunicações e Artes da Universidade de São Paulo (CBD/ECA/USP). reginafa@usp.br

Recebido em: 28/08/2006

Aceito para publicação em: set. 2006 